Keynote Lecture

\title{
Tissue engineering of the gastrointestinal tract for surgical replacement: a nutrition tool of the future?
}

\author{
Tracy C. Grikscheit \\ Department of Surgery, Massachusetts General Hospital and Harvard Medical School, Boston, MA 02114, USA
}

\begin{abstract}
Optimal nutrition depends on the multiple complex functions performed by the gastrointestinal tract, which range from basic functions such as storage, conduit and mechanical processing to more finely regulated capabilities such as vectorial transport, immune defence and cell signalling. Surgical strategies to supply lacking gastrointestinal tract tissues have relied on either replacement by proxy (surgical substitution) or the introduction of prostheses. Tissue engineering seeks to replace missing tissues with engineered tissues that more accurately reproduce the native physiological and anatomical milieu. It is now possible to engineer several areas of the gastrointestinal tract with high fidelity, and to employ tissue-engineered bowel in replacement in animal models. These replacement models have reflected excellent anatomical and physiological recapitulation of native bowel by the tissue-engineered constructs in vivo.
\end{abstract}

Tissue engineering: Gastrointestinal tract replacement: Animal models

\section{Tissue engineering as an evolving field}

Optimal nutrition depends on the multiple complex functions served by the gastrointestinal tract, which range from basic functions such as storage, conduit, and mechanical processing to more finely regulated capabilities such as vectorial transport, immune defence, and cell signalling. Surgical strategies to supply lacking gastrointestinal tract tissues have either relied on replacement by proxy (surgical substitution) or the introduction of prostheses. Tissue engineering seeks to replace missing tissues with engineered tissues that more accurately reproduce the native physiological and anatomical milieu. It is now possible to engineer several areas of the gastrointestinal tract with high fidelity, and to employ tissue-engineered bowel in replacement in animal models.

Replacing the physiological purpose and anatomical location of absent gastrointestinal tract tissue, whether due to congenital deficiency or surgical excision, has traditionally been completed in one of two ways. Either a proxy is supplied or a prosthetic non-living substitution is made, such as a central line and total parenteral nutrition or a colostomy bag serving as a reservoir rather than the living colon.

The limitations of the first approach, native substitution, lie in the dilemma of prioritizing the physiological, psychological and anatomical values of various tissues, and the trade-offs that must be made. In addition, there is a fairly limited supply of donor tissue and it remains inherently different from the tissue it replaces (Grikscheit \& Vacanti, 2002). An example is the replacement of the oesophagus with the stomach, colon or jejunal transfer (Belsey, 1965; Jurkiewicz \& Paletta, 1989; Dreuw et al. 2001; Samuel et al. 2001; Gutschow et al. 2001). The second approach, artificial substitution, has recognized morbidity: material failure; increased rates of infection; the immune system's destruction of foreign material. Non-living material does not adapt or grow.

A third approach, tissue engineering, has increased in popularity in the last 20 years, with the goal of creating living replacement organs and tissues. By creating the exact tissue that is lacking, self-propagation and self-repair may be gained as well as the possibilities of less physiological 
mismatch, rejection and tissue deficit. Progress in the paediatric surgical treatment of short bowel syndrome (Grikscheit \& Vacanti, 2002), cranio-facial defects (Lee et al. 1997) and valve defects is imminent (Bader et al. 1998; O’Brien et al. 1999; Shinoka et al. 2001). Human application of tissue-engineered skin and large-calibre vessels has already occurred successfully (Shinoka et al. 2001). The field of engineered gastrointestinal tract tissue has extended to include all areas of the gastrointestinal tract from the oesophagus to the colon, and even spleen and other solid organs (Grikscheit \& Vacanti, 2002).

\section{Principles of tissue engineering}

Organizing complex three-dimensional functional structures from a combination of cells and structural elements relies on numerous spatial and chemical relationships. The multitudinous approaches taken by tissue engineers can be roughly reduced to in vitro and in vivo designs. There is a requirement for an underlying framework or scaffold for the cells, the proper population of cells and a substitute for the extracellular matrix or extracellular environment. Interactions between cells and extracellular matrix are some of the keys to cell migration, proliferation, differentiation and apoptosis, which are all critical functions for a tissueengineered construct (Mooney \& Langer, 1995).

In vitro models have usually relied on the formation of a bioreactor system or cell patterning for monolayer coculture studies (Folch et al. 1999; Zhang et al. 1999). Bioreactors are dynamic tissue-culture devices that range from simple mechanical designs to more complex systems with more elements of a living physiological system such as $\mathrm{O}_{2}$ exchange, defined flow rates and electrical and mechanical stimulation. The engineering of less complex tissues such as cell sheets only requires a simple method to renew the growth medium to the engineered construct and to avoid stasis. Thus, there has been success with models that agitate a growth medium around a construct that has been seeded with cells, such as a spinner flask or rotating vessel (Freed \& Vunjak-Novakovic, 1997). More elaborate bioreactors have been designed to furnish stretch to skeletal muscle cultures (Vandenburgh et al. 1997), shear to endothelial cells (Wang et al. 1996) or compression to chondrocytes (Buckley et al. 1998). There is good evidence that engineered tissues grown under physiological conditions including strain and pericellular nutrient availability have improved cell morphology, growth characteristics and metabolic activity (Matas et al. 1976; Sutherland et al. 1977; Russell, 1985). In studies of chondrocytes subjected to hydrodynamic forces cell proliferation rates are approximately $50 \%$ greater and the extracellular matrix is improved (Gupta et al. 1991; Balis et al. 1999).

In vivo studies have focused on animals as a 'physiologically-complete bioreactor', with composite constructs implanted into vascularized spaces such as the omentum, mesentery, interscapular fat pad or latissimus dorsi (Vacanti et al. 1988). A substitute for the extracellular matrix in the form of a scaffold is implanted after cell loading onto the construct (Lanza et al. 2000). The construct can be optimized by modifying the polymer itself through chemical engineering, microfabrication of topographic cues including the chemical microenvironment or by prevascularization (Uyama et al. 1993; Bhatia et al. 1998; Kaihara et al. 2000a).

A combination of in vitro and in vivo approaches has solved some simple tissue-engineering problems, and will continue to be equally important for autologous tissue removal, augmentation in the laboratory and eventual in vivo replacement.

\section{Tissue engineering the small intestine}

Of the morbid conditions associated with bowel resection, short bowel syndrome may be the most pyschologically, economically and qualitatively devastating. Characterized by progressive weight loss, malnutrition, vitamin deficiency and infections associated with the vascular access commonly used to support patients with this syndrome (Wilmore et al. 1997), short bowel syndrome usually ensues when less than one-third of the normal small intestine remains, as in cases of massive resection. Surgical attempts to treat this syndrome include bowel transplant (Bueno et al. 1999), reversed segments (Diego et al. 1982) and recirculating loops (Thompson et al. 1984), as well as tapering and lengthening procedures to encourage intestinal mucosa to proliferate (Weber et al. 1982; Pokorny \& Fowler, 1991). However, there is currently no durable surgical solution.

The ideal tissue-engineered intestinal substitute would be anatomically and microbiologically constructed to model the structure and function of native intestine. In addition, as a self-repairing and self-proliferating tissue replacement, tissue-engineered intestine would grow with the patient and require less maintenance or replacement.

Beginning 12 years ago with the observation that fetal intestine transplanted on polymer scaffolds showed proliferation and intestinal morphogenesis (Vacanti et al. 1988), the Boston group has built an expertise in the production of tissue-engineered small intestine. A refinement of these techniques in the past 2 years has led to the generation of better tissue-engineered small intestine and the novel formation of tissue-engineered oesophagus, colon, spleen (Grikscheit et al. 2001, 2002, 2003a,b,c) and stomach (Grikscheit \& Vacanti, 2003). The generation of a composite tissue resembling small intestine generated from intestinal crypt cells paratopically transplanted as epithelial organoid units was first reported by the Boston group in 1998 (Choi et al. 1998). Organoid units are obtained from full-thickness harvests of small intestine. After purification they are loaded onto $10 \mathrm{~mm}$ long $2 \mathrm{~mm}$ non-woven cylindrical polymers made of polyglycolic acid, coated with polylactic acid and implanted into the omentum. Initial experiments showed production of tissue-engineered small intestine with cytodifferentiation and phenotypic maturation as well as apical staining of brush-border enzymes and basolateral staining for laminin. An Ussing chamber study also indicated similar transepithelial resistance between native intestine and the tissue-engineered construct (Choi et al. 1998). On histology, tissue-engineered small intestine has a polarized epithelium with appropriate reconstitution of the other layers of the intestinal wall, and there is substantial vascularization accompanying the growth (Choi et al. 1998). Addition of endothelial cells or specific trophic factors does not seem to 
be necessary. However, a comparison of small bowel resection, partial hepatectomy and porta-caval shunt in addition to the formation of engineered small intestine showed that small bowel resection and porta-caval shunt both resulted in enhanced formation of engineered intestine by morphometric analysis of the neomucosa and cyst dimensions (Kim et al. 1999).

Long-term follow-up after anastomosis of tissueengineered small intestine to native jejunum after 75 or $80 \%$ small bowel resection in male Lewis rats revealed weight gain, bowel patency and significant $(P<0.05)$ increases in the engineered intestine size (Kaihara et al. 2000b; Grikscheit et al. 2003a). The engineered small intestine immune cell population is a function of exposure to lumen antigens and time of harvest, but becomes normal after anastomosis (Perez et al. 2002). In anastomosed tissue-engineered small intestine mucosa harvested at 20 weeks the density and topographical distribution of immune cell subsets was identical to that of normal jejunum. Epithelial mRNA expression topography of $\mathrm{Na}^{+}$-dependent glucose transporters, a bowel $\mathrm{Na}$-glucose cotransporter, is also regenerated in anastomosed engineered small intestine, as is divalent cation transporter 1, an Fe transporter (Tavakkolizadeh et al. 2000). The normal distribution patterns of these transporters argue that the engineered intestine shows a considerable resemblance to native jejunum, and underlines the therapeutic potential of this conduit for patients who lack small bowel.

\section{Tissue engineering the gastrointestinal tract}

With refinements of the organoid protocol for engineered small intestine, larger cysts have been created with a larger surface area, and engineered stomach, oesophagus, spleen and large intestine have also been created (Grikscheit et al. 2001, 2003b). Tissue-engineered large intestine has been studied in a replacement model in vivo with good results both for histology and physiology (Grikscheit et al. $2003 a, b, c)$. After removal of the native colon, a small intestine pouch is often created as a reservoir, but inflammation of the pouch, pouchitis, is a common complication. There are also additional post-colectomy morbidities associated with lack of the physiological large intestinal function. The symptoms associated with pouchitis are not trivial, including altered stool frequency, abdominal cramping, fever, and extraintestinal manifestations (Shen et al. 2001). Although pouchitis is certainly related in part to host factors, which accounts for an increased incidence of pouchitis in ulcerative colitis as compared with familial adenomatous polyposis, the adaptation of small intestine to large intestinal function must also be important (Moskowitz et al. 1986).

A primary advantage of tissue engineering is exact replacement of the function and architecture of the tissue that has been removed rather than replacement by proxy. In rat models substitution of tissue-engineered colon for native large intestine resulted in normal electrolytes, less evidence of dehydration and evidence of bile acid recycling. Animals with a tissue-engineered colon pouch proximal to an ileostomy had a significant $(P<0.05)$ physiological advantage to animals with an end ileostomy alone, including less weight loss and less relative hyponatraemia. With tissueengineered colon animals had decreased stool moisture content by $10 \%$. The presence of a tissue-engineered colon segment additionally raised both serum bile acid content and stool short-chain fatty acids, with higher levels of $n$-butyrate than animals with an end ileostomy. Transit times were more than doubled with tissue-engineered colon (Grikscheit et al. $2003 a, b, c)$.

Tissue-engineered stomach and oesophagus have promising histology and initial replacement-model findings (Grikscheit et al. 2002; Grikscheit \& Vacanti, 2003). Although the stomach and oesophagus have less direct impact on the uptake of nutrients, the use of anatomic and physiological conduit and avoiding the need to be deprived of another portion of the gastrointestinal tract (as in the case of colon substitution for missing oesophagus) have obvious implications for nutritional status.

\section{The future of tissue engineering for nutrition}

With obvious implications for the treatment of many critical nutritional problems, engineered gastrointestinal tract replacements may considerably affect patient care in the coming decade if large animal studies and human results are similar to these initial experimental findings. The ability to deliver engineered gastrointestinal tract tissues with improved surface area, transporter function, immune characteristics and architecture could reverse many devastating nutritional problems. The experimental results reported in the present paper have all relied on omental implantation as a bioreactor system to mature the tissue-engineered portions of the gastrointestinal tract. In cases in which the omentum is no longer present or may not be used, additional engineering solutions may be possible.

With the advent of microelectrical mechanical systems, also used in inertial guidance and navigation (Borenstein et al. 1997), Si micromachining has been used to form an improved scaffold for vascular networks. Trench patterns are etched on $\mathrm{Si}$ and Pyrex templates with resolution to $10 \mu \mathrm{m}$. These patterns recapitulate a vascular network. Endothelial cells and hepatocytes or other parenchymal cells can be cultured on the microelectrical mechanical system template, remaining viable and proliferative, producing albumin (Borenstein et al. 1997). The monolayers can then be lifted and formed into a three-dimensional structure. Further studies have confirmed that microfabrication technology can be used to form large sheets of living tissue, and that micromachining lumen surfaces for endothelial cells allows ordered co-culture. The lifted organized layers have been implanted as a permanent graft.

Tissue engineering has evolved rapidly, primarily through synergy between creative engineers, chemists, surgeons, physicists, biologists and scientists in a number of other fields. Progress has occurred through contemporaneous improvement of constructs, cell-cell relationships and surgical approaches. The evolution of bioreactor devices, including microfabricated milieus, has also played an important role. This combination of mechanical engineering with tissue engineering and surgical research holds promise for tissue-engineered solutions to surgical nutritional 
problems. The ability to specifically engineer the missing portion of the gastrointestinal tract contributing to nutritional imbalance could improve the precision of some nutritional solutions.

\section{Acknowledgement}

Funding was received from the Center for the Integration of Medicine and Innovation in Technology, Department of Defense (no. DAMDIT-99-2-9001).

\section{References}

Bader A, Schilling T, Tebken OE, Brandes G, Herden T, Steinhoff G \& Haverich A (1998) Tissue engineering of heart valves - human endothelial cell seeding of detergent acellularized porcine valves. European Journal of Cardiothoracic Surgery 14, 279-284.

Balis UJ, Behnia K, Dwarakanath B, Bhatia SN, Sullivan SJ, Yarmush ML \& Toner M (1999) Oxygen consumption characteristics of porcine hepatocytes. Metabolic Engineering 1, 49-62.

Belsey R (1965) Reconstruction of the esophagus with left colon. Journal of Thoracic Surgery 49, 33-55.

Bhatia SN, Balis UJ, Yarmush ML \& Bhatia K (1998) Probing heterotypic cell interactions: Hepatocyte function in microfabricated co-cultures. Journal of Biomaterial Science Polymer Edition 9, 1137-1160.

Borenstein JT, Wu KS \& Shay PA (1997) Structural characterization of $\mathrm{p}++\mathrm{Si}$ :B layers for bulk micromachining. Materials for mechanical and optical microsystems: Proceedings of the Materials Research Society Symposium, pp. 20-22. Warrendale, PA: Materials Research Society Press.

Buckley MJ, Banes AJ \& Jordan R (1998) Effects of mechanical strain on osteoblasts in vitro. Journal of Oral Maxillofacial Surgery 48, 276-282.

Bueno J, Ohwada S, Kocoshis S, Mazariegos GV, Dvorchik I, Sigurdsson L, Di Lorenzo C, Abu-Elmagd K \& Reyes J (1999) Factors impacting on the survival of children. Intestinal failure referred for intestinal transplantation. Journal of Pediatric Surgery 34, 27-33.

Choi RS, Riegler M, Pothoulakis C, Kim BS, Mooney D, Vacanti M \& Vacanti JP (1998) Studies of brush border enzymes, basement membrane components, and electrophysiology of tissue-engineered neointestine. Journal of Pediatric Surgery 33, 991-997.

Diego MD, Miguel E, Lucen CM, Salgado GM, Martinez JL \& Garrido HG (1982) Short gut syndrome: A new surgical technique and ultrastructural study of the liver and the pancreas. Archives of Surgery 117, 789-795.

Dreuw B, Fass J, Titkova S, Anurov M, Polivoda M, Ottinger AP \& Schumpelick V (2001) Colon interposition for esophageal replacement: Isoperistaltic or antiperistaltic? Experimental results. Annals of Thoracic Surgery 71, 303-308.

Folch A, Ayon A, Hurtado O, Schmidt MA \& Toner M (1999) Molding of deep polydimethylsiloxane microstructures for microfluidics and biological applications. Journal of Biomechanical Engineering 121, 28-34.

Freed LE \& Vunjak-Novakovic G (1997) Microgravity tissue engineering in vitro. Cell Development Biology 33, 381-385.

Grikscheit T, Alsberg E, Mooney D \& Vacanti J (2003a) Experimental tissue engineered small intestine improves recovery after massive small bowel resection. In: Proceedings of the American Pediatric Surgery Association Meeting, Phoenix, Arizona 2002, pp. 10-11. Phoenix, AZ: American Pediatric Surgical Association Press.
Grikscheit T, Gaissert H \& Vacanti JP (2003b) Tissue engineered esophagus: Substitution by onlay patch or interposition. Journal of Thoracic and Cardiovascular Surgery (In the Press).

Grikscheit TC, Ochoa ER, Ramsanahie A, Whang EE \& Vacanti JP (2001) Tissue engineered colon, characterization and comparison to native colon. Owen Wangensteen Surgical Forum Abstracts 52, 160-161.

Grikscheit T, Ogilvie J, Alsberg E, Mooney D \& Vacanti JP (2003c) Tissue-engineered juvenile spleen protective against pneumococcal infection. Journal of Surgical Research Suppl. (In the Press).

Grikscheit T, Ogilvie J, Ochoa E, Alsberg E \& Vacanti JP (2002) Tissue engineered colon exhibits function in vivo. Surgery 132, 200-204.

Grikscheit T \& Vacanti JP (2002) The history and current status of tissue engineering: the future of pediatric surgery. Journal of Pediatrics Surgery 37, 277-288.

Grikscheit T \& Vacanti JP (2003) Tissue-engineered stomach from autologous and syngeneic tissue. Journal of Surgical Research Suppl. (In the Press).

Gupta S, Aragona E, Vemuru RP, Bhargava KK, Burk RD \& Chowdhury JR (1991) Permanent engraftment and function of hepatocytes delivered to the liver: Implications for gene therapy and liver repopulation. Hepatology 14, 144-149.

Gutschow C, Collard JM, Romagnoli R, Salizzoni M \& Holscher A (2001) Denervated stomach as an esophageal substitute recovers intraluminal acidity with time. Annals of Surgery 233, 509-514.

Jurkiewicz MJ \& Paletta CE (1989) Free jejunal graft. In Current Therapy in Cardiothoracic Surgery, pp. 206-209 [HC Grillo, editor]. Toronto, Ont.: Decker.

Kaihara S, Borenstein J, Koka R, Lalan S, Ochoa ER, Ravens M, Pien H, Cunningham B \& Vacanti JP (2000a) Silicon micromachining to tissue engineer branched vascular channels for liver fabrication. Tissue Engineering 6, 105-117.

Kaihara S, Kim SS, Kim BS, Mooney D, Tanaka K \& Vacanti JP (2000b) Long-term follow-up of tissue engineered intestine after anastomosis to native small bowel. Transplantation 69 , 1927-1932.

Kim SS, Kaihara S, Benvenuta M, Choi RS, Kim BS, Mooney DJ, Taylor GA \& Vacanti JP (1999) Regenerative signals for tissue engineered small intestine Transplantation Proceedings 31, 657-660.

Lanza RP, Langer R \& Vacanti J (2000) Principles of Tissue Engineering. San Diego, CA: Academic Press.

Lee IW, Vacanti JP\& Yoo J (1997) A tissue engineering approach for dural and cranial grafts. Abstracts of the Congress of Neurological Surgeons.

Matas AJ, Sutherland DER, Stefes MW, Mauer SM, Sowe A, Simmons RL \& Najarian JS (1976) Hepatocellular transplantation for metabolic deficiencies: Decrease in plasma bilirubin in Gunn rats. Science 192, 892-894.

Mooney DJ \& Langer R (1995) Engineering biomaterials for tissue engineering: The 10-100 micron size scale. In The Biomedical Engineering Handbook, pp. 1609-1616 [JD Bronzino, editor] Boca Raton, FL: CRC Press.

Moskowitz RL, Shepherd NA \& Nicholls RJ (1986) An assessment of inflammation in the reservoir after restorative proctocolectomy with ileoanal ileal reservoir. International Journal of Colorectal Disease 1, 167-174.

O'Brien MF, Goldstein S, Walsh S, Black KS, Elkins R \& Clarke D (1999) The synergraft valve: a new acellular (nongluteraldehyde-fixed) tissue heart valve for autologous recellularization first experimental studies before implantation. Seminars in Thoracic and Cardiovascular Surgery 11, 194-200. 
Perez A, Grikscheit TC, Blumberg RS, Ashley SW, Vacanti JP \& Whang EE (2002) Tissue engineered small intestine: Ontogeny of the immune system. Transplantation 74, 619-623.

Pokorny WJ \& Fowler CJ (1991) Isoperistaltic intestinal lengthening for short bowel syndrome. Surgery Gynecology and Obstetrics 172, 39-43.

Russell PS (1985) Selective transplantation. Annals of Surgery 201, 255-262.

Samuel M, Burge DM \& Moore I (2001) Gastric tube graft interposition as an oesophageal substitute. Australian and New Zealand Journal of Surgery 71, 56-61.

Shen B, Achkar JP, Lashner BA, Ormsby AH, Remzi FH, Bevins CL, Brzezinski A, Petras RE \& Fazio VW (2001) Endoscopic and histologic evaluation together with symptom assessment are required to diagnose pouchitis. Gastroenterology 121, 261-267.

Shinoka T, Imai Y \& Ikada Y (2001) Transplantation of a tissue engineered pulmonary artery (letter to the Editor). New England Journal of Medicine 344, 532-533.

Sutherland DER, Numata M, Matas AJ, Simmons RL \& Najarian JS (1977) Hepatocellular transplantation in acute liver failure. Surgery 82, 124-132.

Tavakkolizadeh A, Stephen AE, Kaihara S \& Kim S (2000) Epithelial transporter mRNA expression topography in the tissue-engineered small intestine. Owen Wangensteen Abstracts of the American College of Surgeons Surgical Forum 51, 59-61.
Thompson JS, Vanderhoot JA, Antonson DL, Newland JR \& Hodgson P (1984) Comparison of techniques for growing small bowel neomucosa. Journal of Surgery Research 36, 401-406.

Uyama S, Kaufmann PM \& Takeda T (1993) Delivery of whole liver-equivalent hepatocyte mass using polymer devices and hepatotrophic stimulation. Transplantation 55, 932-935.

Vacanti JP, Morse MA, Saltzman WM, Domb AJ, Perez-Atayde A \& Langer R (1988) Selective cell transplantation using bioabsorbable artificial polymers as matrices. Journal of Pediatric Surgery 23, 3-9.

Vandenburgh H, Del Tatto M, Shansky J, LeMaire J \& Raven L (1997) Tissue engineered skeletal muscle organoids for reversible gene therapy. Human Gene Therapy 7, 2195-2200.

Wang DL, Wung BS \& Peng YC \& Wang JJ (1996) Mechanical strain increases endothelin-1 gene expression via protein kinase C pathway in human endothelial cels. Journal of Cell Physiology 163, 400-406.

Weber TR, Vane DW \& Grosfeld JL (1982) Tapering enteroplasty in infants with bowel atresia and short gut. Archives of Surgery 117, 684-688.

Wilmore DW, Byrne TA \& Persinger RL (1997) Short bowel syndrome: New therapeutic approaches. Currents Problems in Surgery 34, 389-444.

Zhang S, Yan L, Altman M, Lassle M, Nugent H, Frankel F, Lauffenburger DA, Whitesides GM \& Rich A (1999) Biological surface engineering: a simple system for cell pattern formation. Biomaterials 20, 1213-1220. 